\title{
Romance and the ozone layer: panel evidence on green behavior in couples
}

\author{
Anja Köbrich León ${ }^{1}$ (D) Janosch Schobin ${ }^{2}$
}

Received: 23 April 2021 / Accepted: 6 December 2021 / Published online: 3 February 2022

(c) The Author(s) 2022, corrected publication 2022

\begin{abstract}
The exploration of the drivers of interpersonal alignment processes in romantic partners is particularly relevant to policies that promote green behavior because social anchoring in families and relationships can undermine effective behavioral change. The present paper aims to investigate the role important life events, such as childbirth, marriage, and the acquisition of real estate, in explaining the alignment of pro-environmental behavior within couples over time. The adoption of a life-course perspective is a novelty. We draw on a representative longitudinal panel data set to investigate the significance of important life events and the distribution of economic power within a relationship for green alignment. The empirical results are double edged. They show that partners who are expecting the birth of their first child are more similar than partners who are not expecting children. After childbirth, partners become significantly more dissimilar. Furthermore, we find evidence of a reconciliation effect. Over time, partners who divorce and continue cohabiting align more than partners who do not divorce.
\end{abstract}

Keywords Similarity Environmental behavior $\cdot$ Couples $\cdot$ Life-cycle perspective . UKHLS

JEL Classification D10 · D91 · Q50

Anja Köbrich León

anja.koebrich@uni-kassel.de

Janosch Schobin

jschobin@uni-kassel.de

1 Department of Economics, University of Kassel, Nora-Platiel-Str. 5, 34109 Kassel, Germany

2 Department of Social Sciences, University of Kassel, Nora-Platiel-Straße 1, 34109 Kassel, Germany 


\section{Introduction}

Romantic relationships are often the center of the social life of the individual. Prior studies of spousal correlations identify similarities in, among others, risk preferences (Di Falco and Vieider 2018; Kimball et al. 2009), stock-market participation (Hellström et al., 2013), and the uptake of smoking (Clark and Etilé, 2006). While numerous cross-sectional studies also reveal similarities in pro-environmental behavior (Grønhøj and Ölander, 2007; Grønhøj and Thøgersen 2011; Longhi 2013; Thøgersen and Grønhøj, 2010), only a few address timing and the question whether alignment processes are punctuated by important life events.

This paper concerns similarities in the pro-environmental behavior of couples and examines the extent to which partners become more similar empirically. The investment model of partnership attachment (Leonhardt et al. 2021; Rusbult et al. 2012) suggests that relationship quality is an economic good that partner co-produce by aligning their behaviors in a life-cycle process of preference socialization through daily interaction (Grønhøj, 2006; Moschis 1987). It predicts that partnership commitment is expressed as a reduction in intrahousehold preference heterogeneity, because highly committed partners renounce personal preferences in order to accommodate each other's interests (Rusbult et al., 2012). This psychological model fits with and informs economic models of intrahousehold resource allocation, which assume that the preferences of household members are heterogeneous and emphasize the dependence of household consumption on the weighted utility functions of all household members (Browning et al. 1994; Browning and Chiappori 1998).

Moreover, the empirical literature on investment model of partnership attachment shows that the strength of commitment depends on the relationship stage of a couple (Leonhardt et al., 2021; Rusbult et al., 2012). This entails that the level of alignment regarding pro-environmental behaviors should change throughout the life-course. Hence, the paper adopts a life-course perspective, which is a novelty. We consider the impact of significant life events, such as marriage, the birth of a first child, and property acquisition, on the alignment process. Considering important life events is also warranted because they might present windows of opportunity for behavioral change. Many pro-environmental behaviors are habitual. Important life events allow habits to be reviewed and new practices to be established. Those practices, in turn, can develop into new routines (Spaargaren, 2003). The paper inquires whether life-changing events, such as the birth of a first child, marriage, or the purchase of a home, change the degree of similarity that partners exhibit in their pro-environmental behavior.

Using two waves of the UK Household Longitudinal Study (UKHLS), we observed absolute difference in the green behavior indices of couples to identify within-couple similarities. The indices are derived from eleven pro-environmental behaviors. We employed a basic difference-in-differences (DiD) approach to estimate changes in the differences between partners' pro-environmental behavior. If partners align their proenvironmental behavior, the difference between them should decrease over time; if the partners diverge, the difference should increase. Our results show that the differences between partners only decrease marginally over time. The results also provide evidence of a double-edged window-of-opportunity effect in pro-environmental partnership 
alignment. One of our findings is that partners become more similar in their proenvironmental behavior before the birth of their first child. After the child is born, they become more dissimilar. Similarly, we find evidence of a reconciliation effect. Divorced partners who remain in the same household align more closely.

Our empirical findings add to the literature on similarities in individual proenvironmental behavior by providing a longitudinal analysis of life-changing events as an explanation of pro-environmental alignment between partners. Some studies examine the similarities between the pro-environmental preferences and behaviors of partners (Grønhøj and Ölander, 2007; Grønhøj and Thøgersen 2011; Longhi 2013; Thøgersen and Grønhøj, 2010). While it is possible to draw inferences about these similarities from previous studies, the channels that underlie the correlations have not yet been examined. Instead of studying cross-sectional correlations, we focus on whether couples become more similar in their green behavior over time, and we consider important life changing events as possible turning points.

Investigating dynamic social interaction effects in adults also contributes indirectly to the literature on the transmission of green behaviors across generations. So much is suggested by recent research on endogenizing preference formation in children through intergenerational transmission (see Bisin and Verdier 2010; Hellström et al., 2020). Several studies also emphasize the relevance of the intergenerational transmission of preferences and behaviors to the socialization of environmental concerns among children (Gotschi et al., 2009; Grønhøj and Thøgersen 2009, 2012; Matthies et al. 2012; Moschis 1987). The socialization of sustainable development into children is assumed to be more effective when it is reinforced by parents with matching preferences. A study of the mechanisms by which important life events change the degree of similarity that partners exhibit in their pro-environmental behaviors is thus warranted.

The remainder of the paper is structured as follows: Sect. 2 briefly describes the data set and the variables that are included in the empirical analysis. The econometric approach is also presented. Section 3 describes and discusses the estimation results, and Sect. 4 concludes.

\section{Data, variables, and econometric approach}

\subsection{Data}

We used the UKHLS, a long-run panel of nationally representative, randomly sampled married and cohabiting individuals, for the empirical analysis of couple-level alignment. Wave 1 (2009-2010) and Wave 4 (2012-2013) contained questions on proenvironmental behaviors and preferences. We combined the two waves, which yielded a total of 98,151 responses from 67,557 distinct individuals. Among the 50,994 individuals who were observed in the 2009-2010 wave, 30,594 were still present in the 2012-2013 one, corresponding to an attrition rate of approximately 40\%, which is in line with attrition levels in comparable household surveys. We then excluded respondents who did not have a partner in either of the two waves or who had changed partners between waves. This reduction yielded a total of 8,249 constant couples (16,498 individuals). In the last step, we also excluded all couples for which there were missing 
dependent-variable values in either of the two waves. This procedure resulted in a balanced panel of 6,349 couples (12,698 individuals) that had been observed on two different occasions. We imputed the independent variables through Markov chain Monte Carlo procedures for handling missing cases. Those procedures are premised on the assumption that all variables in the imputation model follow a joint multivariate normal distribution.

\subsection{Variables}

Our main dependent variable is based on 11 questions on environmental behavior. ${ }^{1} \mathrm{We}$ used the answers to create a mean pro-environmental behavior scale, as proposed by Binder and Blankenberg (2017). In our scale, higher values indicate more environmentfriendly behavior. Our aim was to measure alignment between partners. Accordingly, we created the variable "Green behavior" to capture the absolute differences between the pro-environmental behavior scores of partners and the changes in those differences between the two waves.

We consider important life events (changes in marital status, childbirth, and real estate acquisition) to be our main explanatory variables. Previous work demonstrates that individual characteristics drive pro-environmental behaviors (Stern 2000). Accordingly, we also account for attitudinal factors, such as beliefs in the necessity of climate action, and for socioeconomic factors, such as age, education, and income. Since differences in these factors are likely to influence couples' pro-environmental behavior, we also consider differences in the corresponding level variables.

Appendix 1 contains a detailed description of the variables in the data set. Table 1 overviews the main variables of interest. The couples in the sample overwhelmingly exhibited green behavior and medium-to-strong agreement with the proposition that something needs to be done about climate change, a proxy for pro-environmental attitudes. On average, the differences in green behavior were small, and the differences in green attitudes were even smaller.

About $83 \%$ of the couples in Wave 2009/10 and 88\% of the couples in Wave 2012/13 were married. A small fraction of respondents (4.7\%) married between the waves, as Table 2 indicates. In both waves, most couples did not have children but owned a house. Between the waves, the number of couples that faced a transition to parenthood was equal to the number of couples that entered the empty nest phase. Most respondents reported income above the median. Income distribution tended to be unequal in both waves.

\subsection{Econometric approach}

The effect of interest is the change in the absolute difference between the environmental behavior scale scores of partners who had experienced an important life event and those who had not experienced such events. Therefore, we adopted a basic DiD estimation technique with several categories of contextual factors $j$ and two time periods that

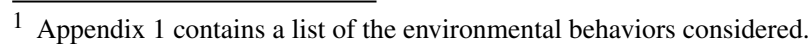




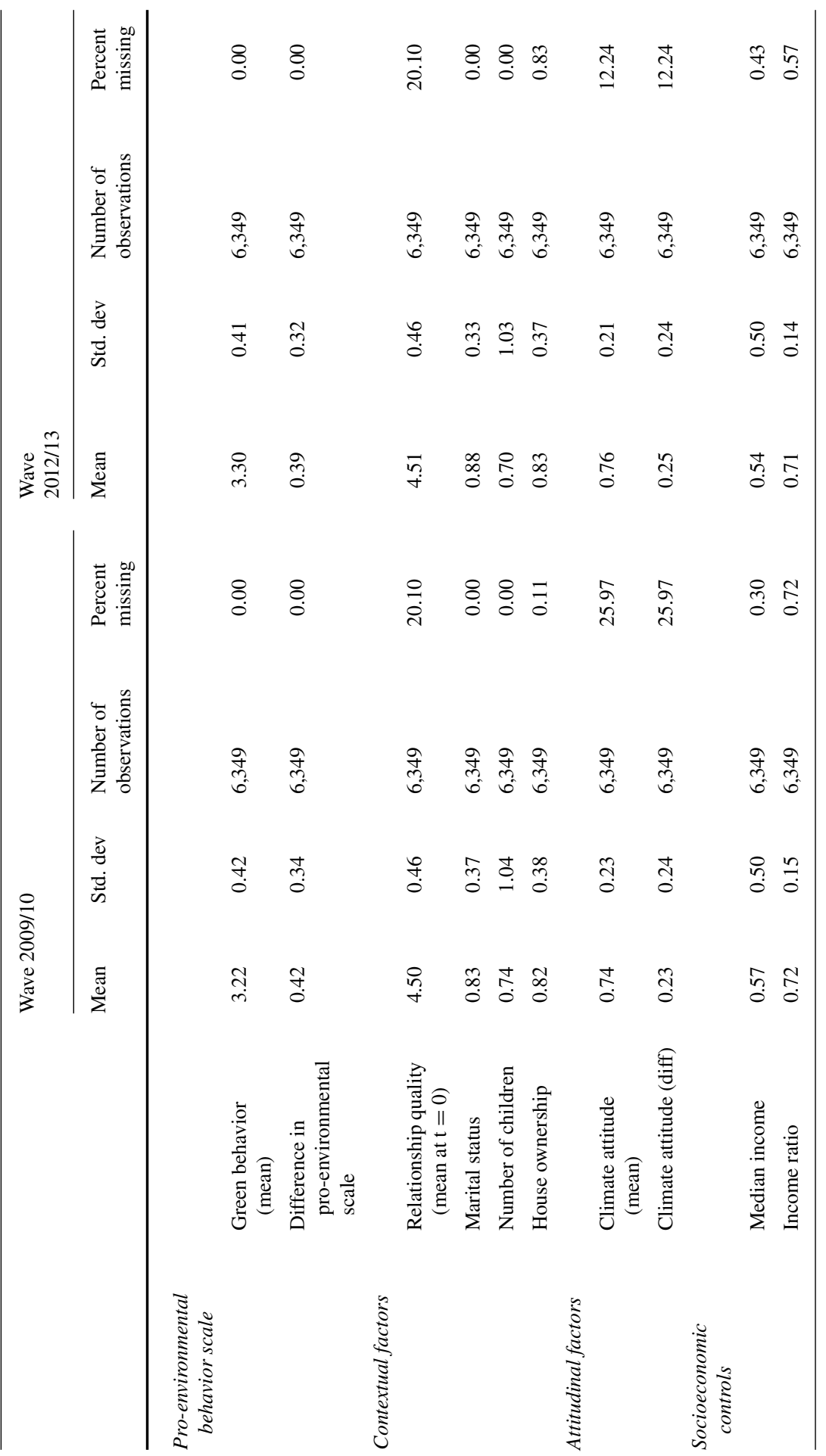




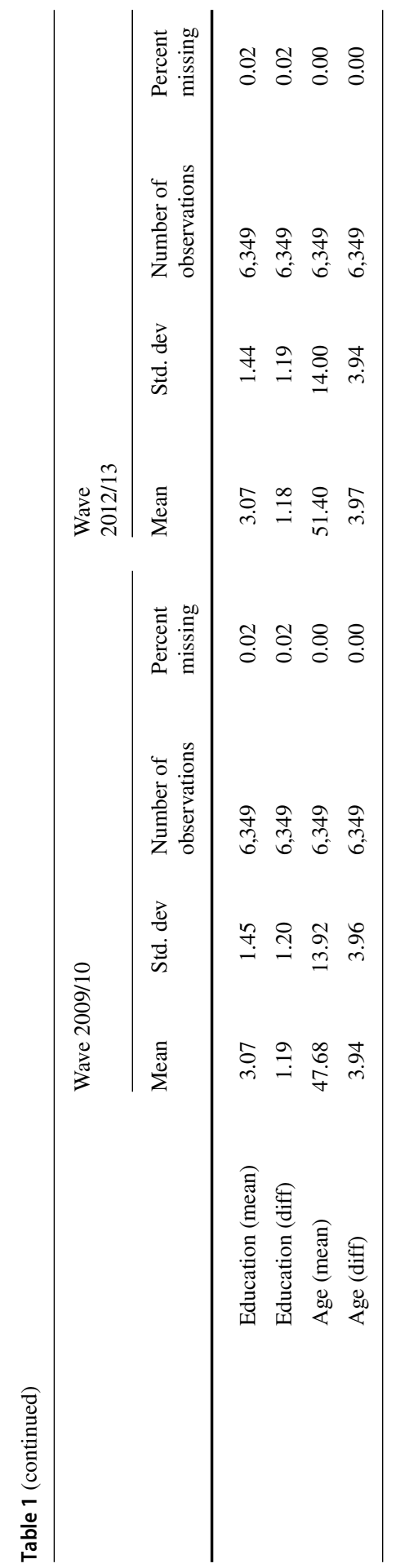


Table 2 Descriptive statistics: change in contextual factors

Observations Mean Std.

dev

Change in marital status (base category: unmarried in both waves)

Entered into marriage between waves

12,698

0.042

0.200

Divorced between waves

12,698

0.004

0.060

Married in both waves

12,698

0.836

0.370

Change in number of children

(base category: no children in both waves)

First child enters $\mathrm{HH}$

12,698

0.044

0.205

Last child leaves HH (empty nest)

12,698

0.053

0.223

Children in $\mathrm{HH}$ in both waves

12,698

0.334

0.472

Change in house ownership (base category: no house ownership in both waves)

Bought a house

0.022

0.145

Sold a house

12,578

0.013

0.112

Owned house in both waves

12,578

$0.789 \quad 0.408$

represent Wave 2009/10 $(t=0)$ and Wave 2012/13 $(t=1)$. Our econometric model is as follows:

$$
\begin{aligned}
\text { Green difference }_{c t}= & \beta_{0}+\beta_{1} \text { Wave }_{t}+\beta_{2} \text { LifeEvent }_{j} \\
& +\beta_{3} \text { LifeEvent }_{j} \times \text { Year }_{t}+\delta^{\prime} X_{c t}+\varepsilon_{c t}
\end{aligned}
$$

where Green difference ett $_{\text {is }}$ is the absolute difference in the pro-environmental behavior scale score for couple $c$ at time $t$. Wave denotes time, and the vector LifeEvent $_{j}$ denotes exposure to important life-changing events. $X_{c t}$ includes attitudinal factors at the relationship level, such as beliefs about the necessity of climate action (climate attitudes) and socioeconomic controls, such as income, education, age, and place of residence. $\varepsilon_{c t}$ is the error term. Wave $e_{t}$ represents time effects, regardless of the occurrence of life changing events. LifeEvent ${ }_{j}$ is equal to 1 if the couple in question experienced a life-changing event (for instance, if they married between $t=0$ and $t=$ 1 ), regardless of the value of $t$, and it is equal to 0 if the couple did not experience such an event. The interaction term Life Event ${ }_{j} \times$ Wave $_{t}$ reveals evidence of the effect of these life-changing events on changes in the difference between the pro-environmental behavior of the partners.

\section{Effects of life-changing events on differences in pro-environmental behavior in couples}

Table 3 presents parameter estimates (including robust cluster t-statistics) from the DiD estimation that we used to evaluate the differences between the pro-environmental 


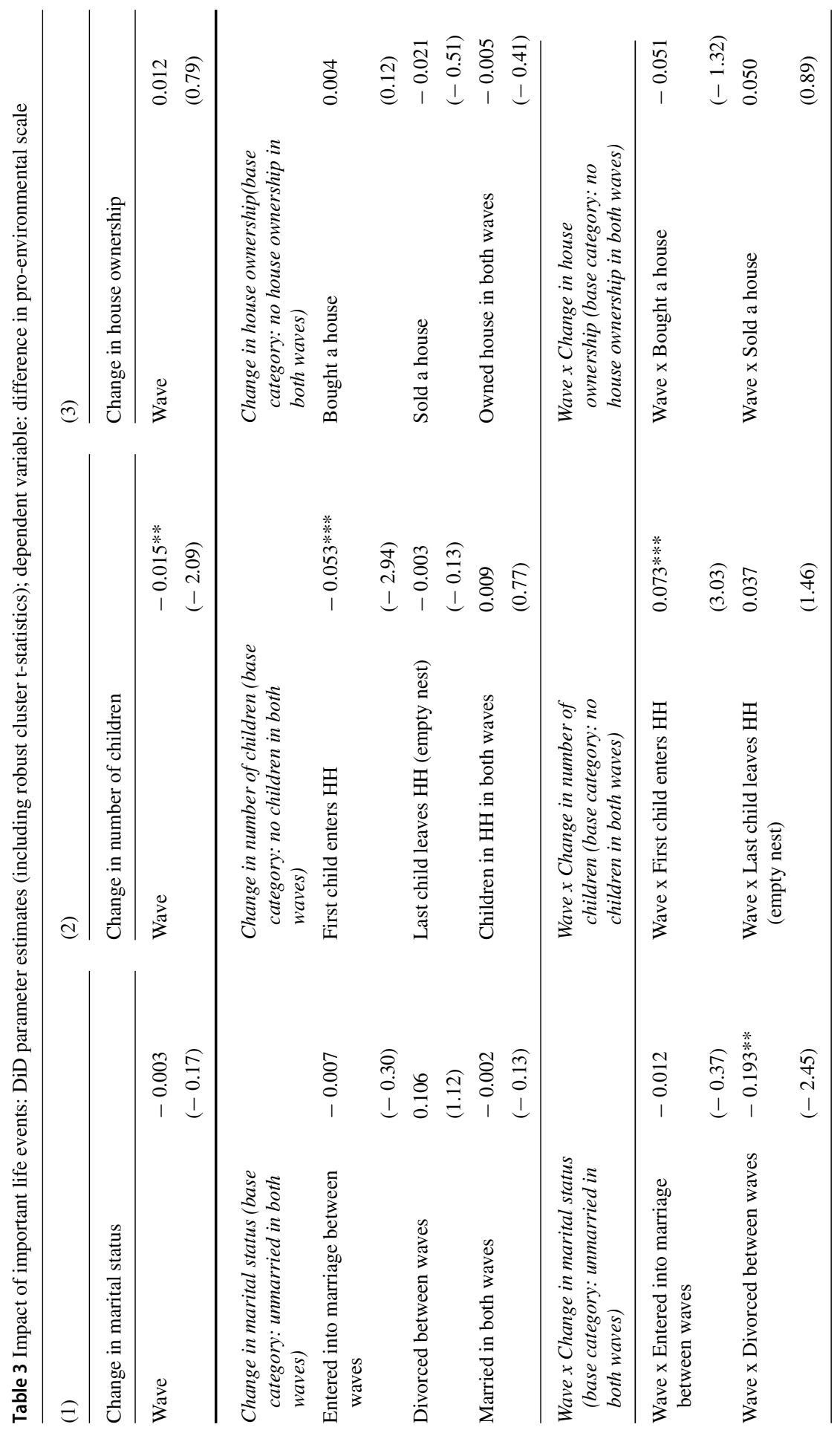




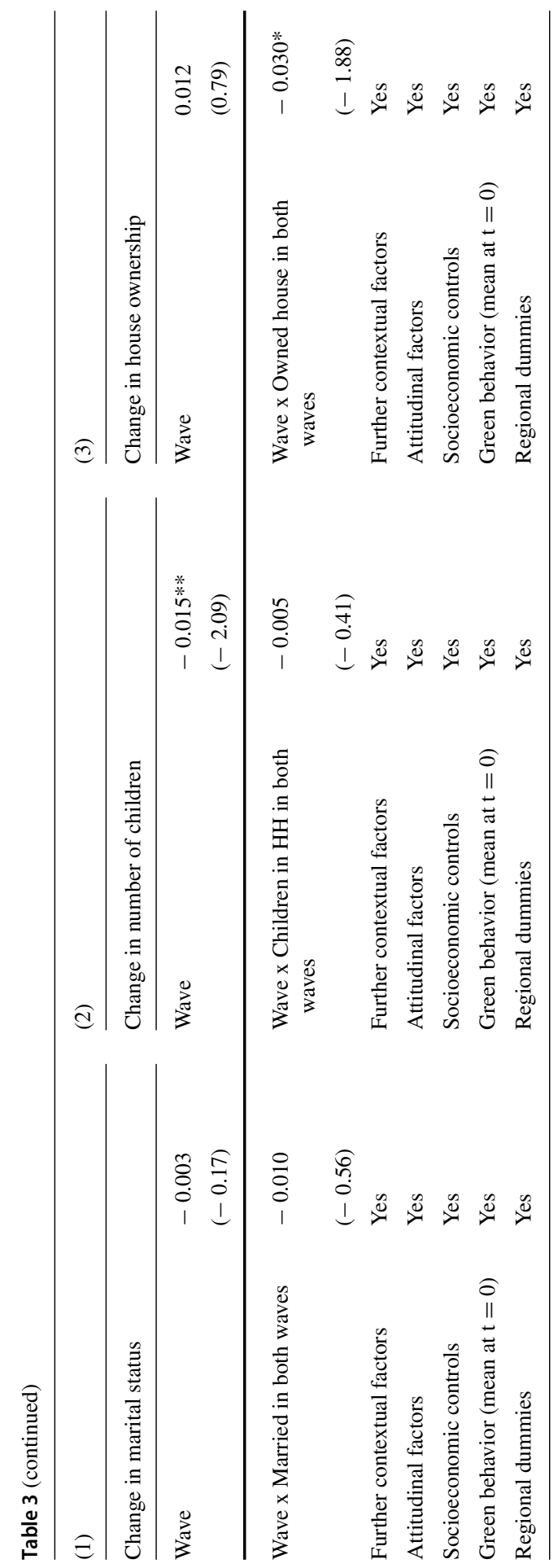


behavior scale scores of couples across the two waves. The analysis accounts for important life-changing events. We expect that couples that experience climactic events should exhibit a more pronounced tendency to change their routines, and thus to align or diverge, than couples that do not. We first considered changes in marital status as determinants of differences in pro-environmental behavior. Specification (1) shows that the pro-environmental behavior scale scores of couples that were not married in either wave exhibit no significant change over time. Similarly, marital status in Wave 2009/10 did not, in and of itself, produce statistically significant variations in behavioral differences. In addition, being married in both waves did not accelerate the alignment effect significantly, as compared to being unmarried in Wave 2012/13. However, changes in marital status between waves did. While marrying was not found to exert a statistically significant influence on the alignment process, the pro-environmental behavior scale scores of partners who had divorced became more similar than those of couples that were unmarried in Wave 20,012/13. Thus, couples that divorced but did not change households (otherwise, they would not have entered the sample) became more similar than unwed couples. It must be noted that the reconciliation effect that we observed is most likely a result of our selection procedure: we compared couples that had continued to cohabit after divorcing, with couples that had not divorced. It stands to reason that the divorced couples under observation were very different from the (unobserved) divorced couples in which one or both partners had left the family home after divorcing. The observed effect is thus not attributable to divorce but, more likely, to a reconciliation that facilitated the continuation of the relationship (and selection into the sample). Studies on divorce and reconciliation show that partners who are interested in reconciliation after divorce often cite differences in attitudes, beliefs, and tastes ("growing apart"), as well as economic problems, as the main reasons for the divorce. Divorced partners who are not interested in reconciliation cite abuse and/or adultery as the main reason for the end of the marriage (Hawkins et al. 2012; Pearce Plauche et al. 2016). These findings suggest that couples that reconcile often address divergences in attitudes, beliefs, and tastes by realigning themselves to each other to address the perceived cause of their divorce. This realignment, in turn, leads to a reduction in the difference between their preferences for environmental behaviors, explaining our finding.

As far as childbirth is concerned, Specification (2) demonstrates that differences in pro-environmental behavior declined significantly over time among couples that were childless ex post. The differences between partners in couples that reported childbirth between the two waves but did not have children in Wave 2009/10 were lower than the same differences in couples that did not have children in either wave but also in the two groups of couples that had children in Wave 2009/10 (the results on the impact of the presence of children in Wave 2009/10 on differences in couple behavior are not statistically significant and are very close to being zero). The implication is that partners probably align their behavior before the birth of their first child. Furthermore, we found a significant decrease in alignment following the birth of a first child.

These findings largely mirror the results of family psychological studies of changes in couples' relationship quality and attachment during the transition to parenthood. The current literature identifies the birth of a first child as an especially dynamic phase in the development of a couple's division of labor and in the allocation of economic 
goods, such as leisure time. The antenatal phase is typically associated with practical preparation processes, such as childproofing, relocating to a larger home, or transitioning to homeownership (Kley and Drobnič, 2019), which entail changes in household tasks and leisure activities. These practical adjustments are accompanied by investments into relationship quality that take the form of shared leisure activities, practices, and routines. Recent research into the typical course of the decline in relationship quality after the transition to parenthood (Doss et. Al 2009; Kluwer 2010; Adamsons 2013) show that the decline in question is mitigated significantly by higher antenatal relationship quality and relationship attachment (Leonhardt et al. 2021; Ter Kuile et al. 2021). This literature suggests that most couples invest in relationship quality and attachment before childbirth in order to buffer the decline in relationship quality that follows it. Overall, these findings show that the period of preparing for a first child is characterized by very strong commitment to the partnership, with no marked tendency to divergence in the division of labor between the genders (Goldberg et al. 1985; Yavorsky et al. 2015). This can explain the high concordance between the green behaviors of antenatal couples in the UKHLS: according to the investment model of partnership attachment (Leonhardt et al. 2021; Rusbult et al. 2012), shared routines and beliefs are means of expressing attachment and stabilizing relationship quality.

Conversely, the studies that focus on the postnatal phase describe a very different dynamic. First, that phase is marked by a substantial change in the division of labor in couples. New parents spend considerably more time on family work after childbirth (Gauthier and Furstenberg 2002). This results in a strong reduction in the availability of leisure time (Cantwell and Sanik 1993; Kluwer 2010; Yavorsky et al. 2015). The redistribution of the increased volume of labor and the reduced amount of leisure time is often gendered, leading to a divergence in temporal and economic constraints. According to economic models of intrahousehold resource allocation, that divergence increases preference heterogeneity (Browning et al. 1994; Browning and Chiappori 1998). This point can be illustrated through one of the environmental behaviors that we included in our environmental behavior scale: using public transportation often is much less convenient for the partner who does most of the childcare, even if both partners preferred it prior to childbirth.

In conclusion, our results are concordant with the findings that show that the birth of a first child puts pressure on the availability of time and on the observance of environmental practices. This pressure may suppress alignment, causing couples that have recently had their first child to diverge more than childless couples. To simplify somewhat, Specification (2) suggests a two-step process. Partners align their proenvironmental behaviors to each other before childbirth (nestmaking). After childbirth, they diverge in order to readapt to the exigencies of parenting (role differentiation). As the estimation results depicted by Specification (3) show, we found several null effects, which must be interpreted with caution. They run counter to our theoretical expectations. Family scientific studies report that the transition to home ownership is regularly linked to family formation (Mulder and Smits 1999; Pearce Plauche et al. 2016; Wiik et al. 2009). That process should be expected to follow the same pattern as that observed around the birth of a first child, that is, couples should invest in the relationship prior to the acquisition of a home, aligning their behaviors. Afterward, they should diverge until they settle into stable family roles. The (non-significant) 
effects in the data cannot rule out such an effect, and it must be noted that the effects of the acquisition of a home point into the expected direction. Moreover, from the perspective of the investment theory of attachment, differences in behavior should remain rather stable or increase very slowly in couples that own homes, mirroring the typical slow long-term decline in relationship quality that is observed in marriages after family formation (Adamsons 2013; Doss et al. 2009; Kluwer 2010). This theoretical expectation is also at odds with the data. While no time effect could be demonstrated for either non-houseowners or for respondents whose ownership status changed, the difference in pro-environmental behavior decreased among couples that owned a house in both waves (compared to non-houseowners). However, the effect that we found is only marginally significant and might therefore reflect a chance finding.

\section{Conclusion and discussion}

Do important life events affect the similarities in the pro-environmental behavior of romantic partners? The paper investigated the alignment of pro-environmental behavior in relationships by using two waves of UKHLS data. We adopted a DiD approach to analyze the effects of important life events on pro-environmental behavior. Our results furnish some evidence of a window of opportunity for the alignment of pro-environmental behavior. As an important life event, the birth of a child disrupts established behaviors and forces couples to review their common pro-environmental behaviors in a two-stage process. First, in the nestmaking phase that precedes childbirth, partners grow closer in their pro-environmental behaviors. Second, in the role differentiation phase, the scarcity of time and practical constraints cause divergence. Notably, in our sample, partners who divorced and continued cohabiting aligned more closely than unmarried couples, suggesting an (unexpected) reconciliation effect.

In summary, we provided correlational evidence for the proposition that important life events drive alignment in the pro-environmental behavior of partners, at least to some extent, and we made progress toward establishing causality through a DiD approach. This finding accords with field experimental evidence of the alignment of spousal risk preferences (Di Falco and Vieider 2018). However, all of the observed effects are small. The initial similarity between couples was already high. One explanation of the limited explanatory power of the results may be that alignment predates cohabitation and marriage. However, the periods before cohabitation are not captured by most longitudinal data sets. Observing the first years of a relationship is particularly important to understanding alignment. Furthermore, our estimates may be biased due to the challenges of estimating social interaction effects from observational data, which result from the absence of exogenous variation. Direct influencing effects, assortative mating, selection effects (Becker 1974), and common social-environment factors (Manski, 2003) can lead to correlation, though biased, between peers' preferences and their behavior in both space and time (Powdthavee, 2009). The extensive literature on assortative mating documents the selection of partners on the basis of similarities in preferences (for risk preferences, see Dohmen et al. (2012); for social preferences, see Tognetti et al. (2014)), personal characteristics, such as education and income (Di Domingue et al. 2014; Greenwood et al. 2014), and the pursuit of public 
goods (Lam 1988). It is conceivable that individuals who behave in an environmentally friendly manner tend to select partners who act similarly. Similarities in environmental behavior can also emerge when partners share the same social environment.

It is possible that the estimation results suffer from simultaneity bias. Most household surveys that measure environmental behavior follow an annual rhythm. However, influence processes among partners likely operate on a shorter time scale-most partners interact every day. From a modeling perspective, the processes of alignment between partners must be treated as being simultaneous (Breznau, 2018). If that is the case, the environmental attitudes and behaviors of partners must be analyzed as endogenous variables. Dynamic simultaneous causation models that include unobserved fixed individual and couple effects can potentially account for simultaneity bias. However, while such estimations are feasible in theory, they are often impracticable. For instance, dynamic panel approaches commonly suffer from weak instruments because second lags are often poor predictors of lagged first differences. Two strategies are commonly employed to resolve these problems: the addition of further lags and lagged differences as instruments and the estimation of the more efficient GMM estimators proposed by Arellano and Bond (1991) and Blundell and Bond (1998). However, this is only feasible for $\mathrm{T}>3$, and $\mathrm{T}>10$ is more realistic in practice. Regrettably, high-quality panel data with a sufficient number of waves that measure pro-environmental behaviors do not, as far as we know, exist.

The last limitation concerns selection bias. Since only cohabitating and married couples are observed in a household panel, the estimates for alignment over time may be biased by the filtering process that unfolds during early couple formation and the transition to cohabitation and marriage. For instance, individuals who are very prone to transitioning to cohabitation or marriage might also be more susceptible to aligning their behavior to that of their partner. All these limitations notwithstanding, our results show that further research on alignment processes in couples is worthwhile and warranted. The results also highlight the need for dense, high-quality panel data on pro-environmental behaviors. This data may be gathered through novel collection approaches, such as multi-actor panels, which are better suited to the observation of couples before cohabitation.

Author contributions Both authors contributed equally to the article and approved the submitted version.

Funding Open Access funding enabled and organized by Projekt DEAL. Financial support for this project by the German Federal Ministry of Education and Research (BMBF) under the dunding priority "FONA 3-Research for Sustainable Development" under grant agreement No. 01LN1708A is gratefully acknowledged.

Data availability There is no public use file available for the data used in the present study. Requests to access the present data should be directed to anja.koebrich@uni-kassel.de.

\section{Declarations}

Conflict of interest The authors declare that they have no known competing financial interests or personal relationships that could have appeared to influence the work reported in this paper. 
Ethical Standards Ethical review and approval were not required for the paper.

Open Access This article is licensed under a Creative Commons Attribution 4.0 International License, which permits use, sharing, adaptation, distribution and reproduction in any medium or format, as long as you give appropriate credit to the original author(s) and the source, provide a link to the Creative Commons licence, and indicate if changes were made. The images or other third party material in this article are included in the article's Creative Commons licence, unless indicated otherwise in a credit line to the material. If material is not included in the article's Creative Commons licence and your intended use is not permitted by statutory regulation or exceeds the permitted use, you will need to obtain permission directly from the copyright holder. To view a copy of this licence, visit http://creativecommons.org/licenses/ by $/ 4.0 /$.

\section{Appendix 1: Variable description}

See Table 4.

Table 4 Variables description

Variables Description

\section{Pro-environmental behavior scale}

Green behavior (mean)

Difference in pro-environmental scale
Mean green behavior of the couple based on the individual pro-environmental behavior scale built using 11 questions on several domains of pro-environmental behaviors

The following questions on the frequency of individual pro-environmental behavior, which were asked on a 6-point Likert scale (1 = "Always", 2 = "Very often", $3=$ "Quite often", 4 = "Not very often", 5 = "Never" and "Not applicable, cannot do this") are taken into account:

"Switch off lights in rooms that aren't being used";

"Put more clothes on when you feel cold rather than putting the heating on or turning it up";

"Decide not to buy something because you feel it has too much packaging",

"Buy recycled paper products such as toilet paper or tissues";

"Take your own shopping bag when shopping";

"Use public transport (e.g., bus, train) rather than travel by car";

"Walk or cycle for short journeys less than 2 or 3 miles";

"Car share with others who need to make a similar journey";

"Take fewer flights when possible";

"Leave your TV on standby for the night";

"Keep the tap running while you brush your teeth"

For those questions, where the scale was reverse coded in the questionnaire, we have consistently recoded the answers so that higher values represent higher levels of pro-environmental behavior. We have also recoded the answer "not applicable" to missing

Absolute difference in partners regarding their individual pro-environmental behavior scale: 0 ("No Difference") -4 ("Completely Opposite Answers") 
Table 4 (continued)

Variables Description

\section{Contextual factors}

Relationship quality (mean at $\mathrm{t}=0$ )

Marital status

Change in marital status

Number of children

Change in number of children

House ownership
Mean perceived relationship of the couple based on the individual scale for the quality of the relationship (only in wave 1) built using 8 questions on several domains of the relationship

The following questions on relationship quality, which were asked on a 6 -point Likert scale ( $1=$ "Never"; $2=$ "Rarely", 3 = "Occasionally", 4 = "More often than not", $5=$ "Most of the time", $6=$ "All of the time") are taken into account:

"Please indicate on each question which best describes your relationship with your partner at the moment:

Have a stimulating exchange of ideas?

Calmly discuss something?

Work together on a project?

How often do you discuss or have you considered divorce, separation or terminating your relationship?

Do you ever regret that you married or lived together?

Do you kiss your partner?

How often do you and your partner quarrel?

How often do you and your partner "get on each other's nerves?"

Marital status: $0=$ "Unmarried"; 1 = "Married"

Change in marital status between waves: $1=$ " Entered into marriage between waves"; 2 = "Divorced between waves"; 3 = "Married in both waves"; 4 = "Unmarried in both waves" (base category)

Number of children in household

Change in number of children in household between waves: 1 = "First child enters HH"; 2 = "Last child leaves HH (empty nest)"; 3 = "Children in HH in both waves"; $4=$ "No children in both waves" (base category

Ownership of home: $0=$ "No"; 1 = "Yes"

\begin{tabular}{|c|c|}
\hline Variables & Description \\
\hline Change in house ownership & $\begin{array}{l}\text { Change in ownership of home between waves: } 1=\text { "Bought a house"; } 2 \\
=\text { "Sold a house"; } 3=\text { "Owned house in both waves"; } 4=\text { "No house } \\
\text { ownership in both waves" (base category) }\end{array}$ \\
\hline
\end{tabular}

Attitudinal factors 
Table 4 (continued)

\begin{tabular}{|c|c|}
\hline Variables & Description \\
\hline \multirow{7}{*}{ Climate attitude (mean) } & $\begin{array}{l}\text { Belief scale averaged over couple. Interpreted as level of belief in the } \\
\text { necessity to act on climate change of the couple }\end{array}$ \\
\hline & $\begin{array}{l}\text { Average over the dichotomous answers: } 0=\text { "No"(No belief in the } \\
\text { necessity to act on climate change) } 1=\text { "Yes" (Strong belief on the } \\
\text { necessity to act on climate change) to the following questions }\end{array}$ \\
\hline & $\begin{array}{l}\text { "The so-called environmental crisis facing humanity has been greatly } \\
\text { Exaggerated." }\end{array}$ \\
\hline & "Climate change is beyond control-it's too late to do anything about it." \\
\hline & $\begin{array}{l}\text { "The effects of climate change are too far in the future to really worry } \\
\text { me." }\end{array}$ \\
\hline & $\begin{array}{l}\text { "It's not worth me doing things to help the environment if others don't do } \\
\text { the same." }\end{array}$ \\
\hline & $\begin{array}{l}\text { "It's not worth Britain trying to combat climate change, because other } \\
\text { countries will just cancel out what we do." }\end{array}$ \\
\hline Climate attitude (diff) & $\begin{array}{l}\text { Absolute difference between partners regarding the climate "belief scale: } \\
\text { Min =0 "No difference - Max = } 1 \text { "Completely opposite answers" }\end{array}$ \\
\hline Variables & Description \\
\hline
\end{tabular}

\section{Socioeconomic controls}

Median income

Income ratio

Education (mean)

Education (diff)

Age (mean)

Age (diff)

Country
Gross household income above sample mean: $0=$ "No"; 1 = "Yes"

Absolute income ratio between partners in couple calculated as:

$\frac{\left|0.5-\frac{\text { incomepartner }}{\text { coupleincome }}\right|}{0.5}: 0=$ "Both have same income";-1 = "One Partner has all income

Average of highest educational attainment ever reported over couple: $0=$ No qualification"; 1 = Other qualification"; $2=$ "GCSE, etc."; $3=$ A-level, etc."; 4 = Other higher degree"; 3 = "Degree"

Absolute Difference of highest educational between partners in couple: $\operatorname{Min}=0, \operatorname{Max}=5$

Average age of partners in couple

Absolute difference of age between partners in couple

Country of residence: $1=$ England, $2=$ Wales, $3=$ Scotland, $4=$ Northern Ireland

\section{Appendix 2: Additional tables}

See Tables 5, 6 and 7. 
Table 5 Impact of change in marital status: DiD parameter estimates (including robust cluster t-statistics); dependent variable: difference in pro-environmental scale

Change in marital status

Wave

$-0.003$

$(-0.17)$

Change in marital status (base category: unmarried in both waves)

Entered into marriage between waves

$-0.007$

$(-0.30)$

Divorced between waves

0.106

(1.12)

Married in both waves

$-0.002$

$(-0.13)$

Wave $x$ Change in marital status (base category: unmarried in both waves)

Wave $x$ Entered into marriage between waves

$-0.012$

$(-0.37)$

Wave x Divorced between waves

$-0.193^{* *}$

$(-2.45)$

Wave x Married in both waves

$-0.010$

$(-0.56)$

Pro-environmental behavior scale

Green behavior (mean at $\mathrm{t}=0$ )

$-0.048 * * *$

$(-6.35)$

Contextual factors

Relationship quality (mean at $\mathrm{t}=0$ )

$-0.033 * * *$

$(-3.95)$

Number of children

0.005

(1.44)

House ownership

$-0.022 * *$

$(-2.37)$

Attitudinal factors

Climate attitude (mean)

0.006

$(0.35)$

Climate attitude (diff)

$0.035^{* *}$

Socioeconomic controls

Median income

Income ratio 
Table 5 (continued)

Change in marital status

Median income

Education (diff)

0.002

Age (mean)

0.000

$(-0.54)$

Age (diff)

Regional dummies (base category $=$ England)

Wales

Scotland

Northern Ireland

0.008

Constant

$0.718^{* * * *}$

(13.64)

The table reports the parameter estimates and the corresponding cluster-robust t-statistics for each explanatory variable in parentheses. The number of observations is 12,698. “*” (“**," “***”) means that the corresponding parameter is different from 0 at the $10 \%(5 \%, 1 \%)$ significance level

Table 6 Impact of empty nest: DiD parameter estimates (including robust cluster t-statistics); dependent variable: difference in pro-environmental scale

\section{Empty nest}

Wave

$$
\begin{aligned}
& -0.015 * * \\
& (-2.09)
\end{aligned}
$$

Change in number of children (base category: no children in both waves)

First child enters $\mathrm{HH}$

$$
-0.053^{* * *}
$$

Last child leaves HH (empty nest)

$-0.003$

$(-0.13)$

Children in $\mathrm{HH}$ in both waves

Wave $x$ Change in number of children (base category: no children in both waves)

Wave $x$ First child enters HH

Wave x Last child leaves HH (empty nest) 
Table 6 (continued)

\section{Empty nest}

Wave $\mathrm{x}$ Children in $\mathrm{HH}$ in both waves

$-0.005$

$(-0.41)$

Pro-environmental behavior scale

Green behavior (mean at $\mathrm{t}=0$ )

$-0.047 * * *$

$(-6.32)$

\section{Contextual factors}

Relationship quality (mean at $\mathrm{t}=0$ )

$-0.033 * * *$

$(-3.93)$

Marital status

$-0.004$

$(-0.43)$

House ownership

$-0.022 * *$

$(-2.41)$

Attitudinal factors

Climate attitude (mean)

0.006

Climate attitude (diff)

Socioeconomic controls

Median income

0.006

Education (diff)

Age (mean)

0.000

Age (diff)

0.001

Regional dummies (base category $=$ England)

Wales

Scotland

Northern Ireland

Constant

The table reports the parameter estimates and the corresponding cluster-robust t-statistics for each explanatory variable in parentheses. The number of observations is 12,698. "**" (“**," "****) means that the corresponding parameter is different from 0 at the $10 \%(5 \%, 1 \%)$ significance level 
Table 7 Impact of change in house ownership: DiD parameter estimates (including robust cluster t-statistics); dependent variable: difference in pro-environmental scale

Change in house ownership

Wave

Change in house ownership (base category: no house ownership in both waves)

Bought a house

Sold a house

Owned house in both waves

$-0.005$

$(-0.41)$

Wave $x$ Change in house ownership (base category: no house ownership in both waves)

Wave $x$ Bought a house

$(-1.32)$

Wave $\mathrm{x}$ Sold a house 0.050

Wave x Owned house in both waves

Pro-environmental behavior scale

Green behavior (mean at $\mathrm{t}=0$ )

$-0.048 * * *$

$(-6.38)$

Contextual factors

Relationship quality (mean at $\mathrm{t}=0$ )

$-0.033 * * *$

$(-3.98)$

Marital status

$-0.004$

$(-0.44)$

0.005

Number of children

Attitudinal factors

Climate attitude (mean)

Climate attitude (diff)

Socioeconomic controls

Median income 
Table 7 (continued)

Change in house ownership

Age (mean)

Age (diff)

Regional dummies (base category = England)

Wales

Scotland

Northern Ireland

Constant

The table reports the parameter estimates and the corresponding cluster-robust t-statistics for each explanatory variable in parentheses. The number of observations is 12,698. “*” (“**," “***”) means that the corresponding parameter is different from 0 at the $10 \%(5 \%, 1 \%)$ significance level

\section{References}

Adamsons K (2013) Predictors of relationship quality during the transition to parenthood. J Reprod Infant Psychol 31(2):160-171

Arellano M, Bond S (1991) Some tests of specification for panel data: monte carlo evidence and an application to employment equations. Rev Econ Stud 58(2):277

Becker GS (1974) A theory of marriage: part II. J Polit Econ 82(2):S11-S26

Binder M, Blankenberg A-K (2017) Green lifestyles and subjective well-being: more about self-image than actual behavior? J Econ Behav Organ 137:304-323

Bisin A, Verdier T (2010) The economics of cultural transmission and socialization. National Bureau of Economic Research, Cambridge, MA

Blundell R, Bond S (1998) Initial conditions and moment restrictions in dynamic panel data models. J Econ 87(1):115-143

Breznau N (2018) Simultaneous feedback models with macro-comparative cross-sectional data. Met Data Anal 12(2):265-308. https://doi.org/10.12758/mda.2017.07

Browning M, Chiappori PA (1998) Efficient intra-household allocations: a general characterization and empirical tests. Econometrica 66(6):1241

Browning M, Bourguignon F, Chiappori P-A, Lechene V (1994) Income and outcomes: a structural model of intrahousehold allocation. J Polit Econ 102(6):1067-1096

Cantwell ML, Sanik MM (1993) Leisure before and after parenthood. Soc Indic Res 30(2-3):139-147

Clark AE, Etilé F (2006) Don't give up on me baby: spousal correlation in smoking behaviour. J Health Econ 25(5):958-978

Di Falco S, Vieider FM (2018) Assimilation in the risk preferences of spouses. Econ Inq 56(3):1809-1816

Di Domingue BW, Fletcher J, Conley D, Boardman JD (2014) Genetic and educational assortative mating among US adults. Proc Natl Acad Sci 111(22):7996-8000

Dohmen T, Falk A, Huffman D, Sunde U (2012) The intergenerational transmission of risk and trust attitudes. Rev Econ Stud 79(2):645-677 
Doss BD, Rhoades GK, Stanley SM, Markman HJ (2009) The effect of the transition to parenthood on relationship quality: an 8-year prospective study. J Pers Soc Psychol 96(3):601-619

Gauthier AH, Furstenberg FF (2002) The transition to adulthood: a time use perspective. Ann Am Acad Pol Soc Sci 580(1):153-171

Goldberg WA, Michaels GY, Lamb ME (1985) Husbands' and wives' adjustment to pregnancy and first parenthood. J Fam Issues 6(4):483-503

Gotschi E, Vogel S, Lindenthal T, Larcher M (2009) The role of knowledge, social norms, and attitudes toward organic products and shopping behavior: survey results from high school students in Vienna. J Environ Educ 41(2):88-100

Greenwood J, Guner N, Kocharkov G, Santos C (2014) Marry your like: assortative mating and income inequality. Am Econ Rev 104(5):348-353

Grønhøj A (2006) Communication about consumption: a family process perspective on 'green' consumer practices. J Consum Behav 5(6):491-503

Grønhøj A, Ölander F (2007) A gender perspective on environmentally related family consumption. J Consum Behav 6(4):218-235

Grønhøj A, Thøgersen J (2009) Like father, like son? Intergenerational transmission of values, attitudes, and behaviours in the environmental domain. J Environ Psychol 29(4):414-421

Grønhøj A, Thøgersen J (2011) Feedback on household electricity consumption: learning and social influence processes. Int J Consum Stud 35(2):138-145

Grønhøj A, Thøgersen J (2012) Action speaks louder than words: the effect of personal attitudes and family norms on adolescents' pro-environmental behaviour. J Econ Psychol 33(1):292-302

Hawkins AJ, Willoughby BJ, Doherty WJ (2012) Reasons for divorce and openness to marital reconciliation. J Divorce Remarriage 53(6):453-463

Hellström J, Zetterdahl E, Hanes N (2013) Loved ones matter: family effects and stock market participation Umeå Economic Studies 865 Umeå University, Department of Economics. https://ideas.repec.org/p/ hhs/umnees/0865.html

Hellstrrm J, Lapanan N, Olsson R (2015) Intergenerational transmission of pro-social values: socially responsible investment among parents and adult children SSRN Electron J

Hellström J, Lapanan N, Olsson R (2020) Socially responsible investments among parents and adult children. Eur Econ Rev 121, 103328. https://doi.org/10.1016/j.euroecorev.2019.103328

Kimball MS, Sahm CR, Shapiro MD (2009) Risk preferences in the PSID: individual imputations and family covariation. Am Econ Rev 99(2):363-368

Kley S, Drobnič S (2019) Does moving for family nest-building inhibit mothers' labour force (re-)entry? Demogr Res 40:155-184

Kluwer ES (2010) From partnership to parenthood: a review of marital change across the transition to parenthood. J Fam Theory Rev 2(2):105-125

Lam D (1988) Marriage markets and assortative mating with household public goods: theoretical results and empirical implications. J Hum Resour 23(4):462

Leonhardt ND, Rosen NO, Dawson SJ, Kim JJ, Johnson MD, Impett EA (2021) Relationship satisfaction and commitment in the transition to parenthood: a couple-centered approach. J Marriage Family 84(1):80-100. https://doi.org/10.1111/jomf.12785

Longhi S (2013) Individual pro-environmental behaviour in the household context, ISER Working Paper Series [Colchester], 31 pp http://hdl.handle.net/10419/91690

Manski CF (2003) Identification problems in the social sciences and everyday life. South Econ J 70(1):11

Matthies E, Selge S, Klöckner CA (2012) The role of parental behaviour for the development of behaviour specific environmental norms - the example of recycling and re-use behaviour. J Environ Psychol 32(3):277-284

Moschis GP (1987) Consumer socialization: a life-cycle perspective. Lexington Books, Lexington, Mass.

Mulder CH, Smits J (1999) First-time home-ownership of couples: the effect of inter-generational transmission. Eur Sociol Rev 15(3):323-337

Pearce Plauche H, Marks LD, Hawkins AJ (2016) Why we chose to stay together: qualitative interviews with separated couples who chose to reconcile. J Divorce Remarriage 57(5):317-337

Powdthavee N (2009) I can't smile without you: spousal correlation in life satisfaction. J Econ Psychol 30(4):675-689

Rusbult CE, Agnew CR, Arriaga XB (2012) The investment model of commitment processes. In: van Lange P, Kruglanski A, Higgins E, van Lange PA (eds) Handbook of theories of social psychology, 2. Sage, Los Angeles, Calif., pp 218-231 
Spaargaren G (2003) Sustainable consumption: a theoretical and environmental policy perspective. Soc Nat Resour 16(8):687-701

Stern PC (2000) New environmental theories: toward a coherent theory of environmentally significant behavior. J Soc Issues 56(3):407-424

Ter Kuile H, Finkenauer C, van der Lippe T, Kluwer ES (2021) Changes in relationship commitment across the transition to parenthood: pre-pregnancy happiness as a protective resource. Front Psychol 12:622160

Thøgersen J, Grønhøj A (2010) Electricity saving in households-a social cognitive approach. Energy Policy 38(12):7732-7743

Tognetti A, Berticat C, Raymond M, Faurie C (2014) Assortative mating based on cooperativeness and generosity. J Evol Biol 27(5):975-981

Wiik KA, Bernhardt E, Noack T (2009) A study of commitment and relationship quality in Sweden and Norway. J Marriage Fam 71(3):465-477

Yavorsky JE, Dush CMK, Schoppe-Sullivan SJ (2015) The production of inequality: the gender division of labor across the transition to parenthood. J Marriage Fam 77(3):662-679

Publisher's Note Springer Nature remains neutral with regard to jurisdictional claims in published maps and institutional affiliations. 